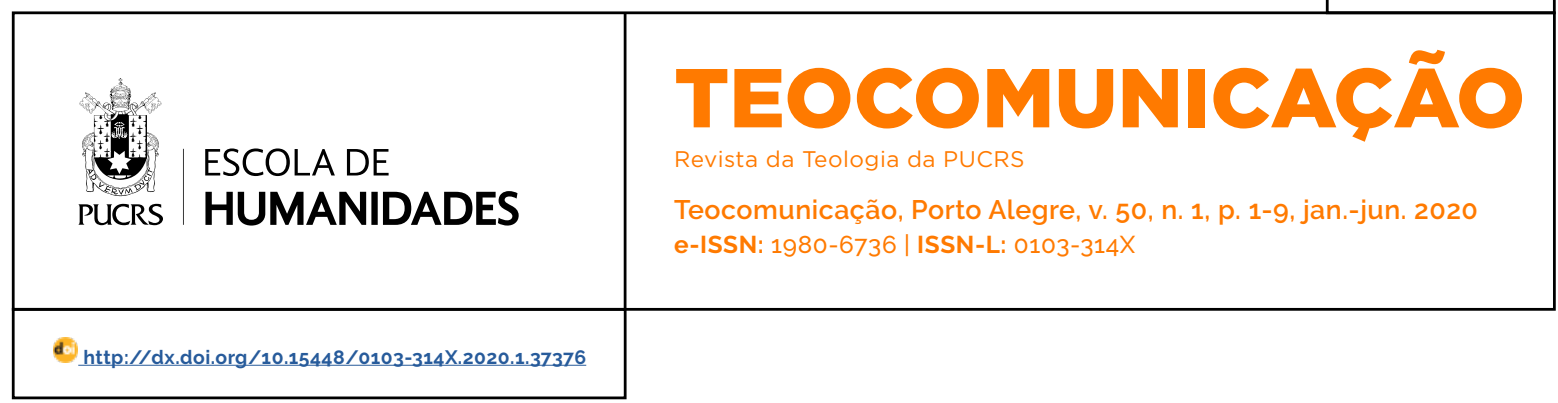

SEÇÃO DOSSIÊ/ ARTIGO ORIGINAL

\title{
Contribuições da psicologia para as vivências juvenis
}

Contributions of psychology to youth lived experiences

\section{Suzana Filizola \\ Brasiliense Carneiro ${ }^{1}$}

orcid.org/0000-0001-8425-4224

suzanafilizola@gmail.com

\section{Maria Camila Mahfoud \\ Marcoccia $^{2}$ \\ orcid.org/0000-0002-7623-2727 \\ camilamarcoccia@gmail.com}

Recebido em: 17 mar. 2020.

Aprovado em: 7 abr. 2020

Publicado em: 5 nov. 2020
Resumo: Esse artigo tem por objetivo ilustrar algumas vivências juvenis que têm se apresentado na atualidade bem como, ilustrar possibilidades de compreensão dessas vivências a partir do dinamismo próprio do eu apresentado por Edith Stein e da noção de experiência elementar de Luigi Giussani. Para tanto, discutimos os relatos de dois jovens que vivem no bairro do Uruguai, região periférica de Salvador, Bahia, e apontamos a contribuição de uma ação clínica inspirada nesses autores, e cujo trabalho se volta para a elaboração da experiência. Ao centrar-se sobre a experiência do paciente, o psicólogo vai além da mera compreensão cognitiva. Ele favorece um encontro humano que revela ao outro a sua dinâmica própria e o sentido da sua existência, mesmo nas experiências de sofrimento.

Palavras-chave: Juventude. Edith Stein. Luigi Giussani. Psicologia clínica. Fenomenologia.

Abstract: This article aims to illustrate some youth experiences that have been presented today, as well as illustrate possibilities for understanding these experiences from the self-dynamism presented by Edith Stein and the notion of elementary experience by Luigi Giussani. To this end, we discuss the reports of two young people who live in the neighborhood of Uruguay, in the peripheral region of Salvador, Bahia, and point out the contribution of a clinical action inspired by these authors, whose work focuses on the elaboration of the experience. By focusing on the patient's experience, the psychologist goes beyond mere cognitive understanding. It favors a human encounter that reveals to the other its own dynamics and the meaning of its existence, even in the experiences of suffering. Keywords: Youth. Edith Stein. Luigi Giussani. Clinical psychology. Phenomenology.

\section{Introdução}

O presente artigo tem por objetivo ilustrar a contribuição da psicologia para a compreensão das vivências juvenis a partir da leitura de relatos de dois jovens à luz da fenomenologia de Edith Stein e da noção de Experiência Elementar de Luigi Giussani. Os relatos foram colhidos no contexto de uma pesquisa de doutorado em Psicologia Clínica ${ }^{3}$ que buscou compreender o processo de desenvolvimento humano em contexto de violência.

Não nos propomos realizar uma análise exaustiva das vivências colhidas e do percurso formativo desses dois jovens, mas antes, ilustrar a dinâmica juvenil como tem se apresentado na atualidade, a partir de um recorte dos relatos de Thais (22 anos) e de Juliano (25 anos). Trata-se de experiências dolorosas e sofridas, da qual comungam muitos jovens, sobretudo aqueles que vivem nas periferias e que sofrem dupla discriminação por serem negros e viverem em situação de pobreza.
Artigo está licenciado sob forma de uma licença Creative Commons Atribuição 4.0 Internacional. 
Ao mesmo tempo, nos propomos a realizar uma compreensão dessas experiências a partir dos sentidos que elas desvelam, e que nos permitem captar um movimento antropológico de base que aponta para exigências humanas comuns e para um apelo de realização que sustenta uma prática psicológica pautada sobre a esperança, mesmo nas situações mais adversas. Nessa perspectiva, uma experiência de solidão, por exemplo, desvela não apenas uma condição de isolamento, mas uma necessidade e uma possibilidade humana de concretização de relações interpessoais empáticas e de acolhimento.

É nesse sentido que buscamos apontar a contribuição da psicologia para a compreensão das vivências juvenis, ou seja, pela possibilidade de revelar as experiências de dor e sofrimento que os jovens experimentam, mas ao mesmo tempo, de vislumbrar o potencial de realização de si contido nesse mesmo sofrimento.

\section{A experiência juvenil se desvela nos relatos de Thaís e de Juliano \\ 1.1 Thais}

Thaís é uma jovem de 22 anos. É a mais velha de cinco irmãos, que ajudou a cuidar desde os 7 anos. Morou com seus pais em um bairro da periferia de Salvador até os 21 anos, época em que se mudou para o Uruguai. Acompanhou seus pais na Igreja Cristã Pentecostal até os 16 anos, e reclamava por não poder usar outro tipo de roupa além do "saião", que era motivo de bullying entre os colegas da escola:

O meu mundo que eu tinha antes era desprezivel porque ninguém me dava atenção, eu era considerada a menina nerd na escola mesmo. Ai eu faltava aula porque os meninos, os garotos humilhavam porque eu era uma menina cristã que vivia de acordo com o Evangelho, de saião e coisas, então eu passava muito preconceito na escola, e no meu bairro eu não tinha amizades porque ninguém queria saber de uma menina cristã que andava de saião lá embaixo. Então eu só andava em casa (Thaís, informação verbal). ${ }^{4}$
Além da dificuldade de relacionamento, Thaís relata várias situações de sofrimento enfrentadas na infância e na juventude, tais como dificuldade financeira da familia; "ignorância do pai" que a impedia de sair de casa e usava da força física em lugar do diálogo para educar; tentativa de estupro; e uma anemia profunda (anorexia) que quase a levou a óbito. Com relação a essa última experiência, conta que se sentia mal por ser considerada - e se achar - "gorda", fugindo do padrão de beleza socialmente imposto. A esse respeito relata:

Sobre a minha beleza, fiquei anorexa (sic), corri risco de morte e fiquei no leito de morte praticamente, e nisso assim... que quando eu comia alguma coisa, tudo o que eu comia eu tinha que botar vinagre porque o povo falava: "- Ah, vinagre emagrece, deixa o corpo light, não sei o que". Até em café, invés do açúcar eu botava vinagre. Pães... Até quando eu ia escovar os dentes, botava pasta e eu punha vinagre. E ensaboava com vinagre. Então isso, assim, né? Nisso tudo, nesse processo todo, eu tive anemia profunda, agora não posso ter filho e o... o meu grande sonho é ser mãe! E eu não posso mais ter essa oportunidade. Com isso tudo deu fraqueza no meu corpo, eu faço a minha dança, faço coisas, mas também tenho minhas dificuldades, mas eu não falo a ninguém. Fico tonta, mas eu não falo a ninguém, mas eu sei que a dança vai me aliviar. Tipo um vício, sabe? Um negócio assim que... só aquilo ali... (Thaís, informação verbal). ${ }^{5}$

Thaís conta que era tímida e que sofria calada. Não sentia o apoio nem mesmo das amigas, cujas relações frágeis e de desconfiança a levavam a querer mostrar-se sempre solicita e forte, escondendo o sofrimento. O que a ajudava era o refúgio nos livros, nos filmes e na dança, que a fazia experimentar liberdade e "alívio" em meio à realidade "sufocante".

Eu andava pelas ruas vagando assim, sem destino. Quando eu parava num canto, era dança. Chegava numa praia onde não tinha ninguém, ninguém, sem ninguém! Pronto. Chegava lá no meu canto, pronto. Expressava os meus sentimentos na fala, nos gestos também e na dança. Depois em seguida botava a minha música e dançava. Daí... e quando saía daquilo e voltava para o meu mundo, o mundo real de todos os seres humanos, eu só vivia na solidão,

\footnotetext{
4 Entrevista de Thaís concedida à pesquisadora Suzana Filizola Brasiliense Carneiro, no contexto da pesquisa de doutorado $A$ formação humana em contexto de violência: uma compreensão clínica a partir da fenomenologia de Edith Stein, na cidade de Salvador, BA, Brasil, no dia 10 de novembro de 2014

5 Entrevista de Thaís concedida à pesquisadora Suzana Filizola Brasiliense Carneiro, no contexto da pesquisa de doutorado $A$ formação humana em contexto de violência: uma compreensão clínica a partir da fenomenologia de Edith Stein, na cidade de Salvador, BA, Brasil, no dia 10 de novembro de 2014
} 
assim, era dificil de eu ter um riso e quando eu ria, era um rir, assim, interpretado sabe de atriz, que não é de sentimento... Não vinha de dentro, entendeu? Eram artificiais, entendeu? (Thais, informação verbal). ${ }^{6}$

Segundo o relato, dois acontecimentos foram decisivos para a decisão de Thaís de sair de casa e de buscar novo sentido para sua vida: o assassinato do irmão que se envolvera com o tráfico na expectativa de oferecer uma vida melhor aos pais, e o namoro com o professor de dança de um espaço cultural que ela passou a frequentar após contato pela internet. Thaís identifica a sua mudança para o bairro do Uruguai como um marco na sua vida. Conta como ali se sentiu acolhida, passou a se abrir para o outro e a explorar um novo mundo que até então havia sido privada.

Eu não achava lugar onde dançar, onde alguém me ensinasse a dançar e que me acolhesse de acordo como um ser humano devia ser acolhido. E aqui, através de uma pesquisa na internet, encontrei esse Espaço Cultural e o professor me acolheu [...]. E fui crescendo cada vez mais [...] Eu aqui encontrei vida, aqui encontrei o meu mundo (Thais, informação verbal) ${ }^{7}$

\section{A acolhida e a escuta que recebeu no Espaço} Cultural não foi apenas em relação à música, mas também em relação aos sofrimentos vividos. Descobriu uma rede de apoio e pôde partilhar com outros jovens que tinham vivido situações semelhantes. Essa experiência a ajudou a se abrir e a não querer mais carregar a dor sozinha, conforme ilustra o relato a seguir:

[...] faz três semanas que eu comecei a não guardar isso, jogar tudo, contar para todo mundo e eu não quero mais guardar nada dentro de mim. Eu aprendi isso [...] eu estou tentando assim, amenizar mais a minha dor porque é muito peso de estupro, de morte na familia, de dificuldade financeira e na educação também. E é muito processo, muito processo pra uma cabeça só entendeu? (Thaís, informação verbal). ${ }^{8}$
Conta que passou a viver uma nova etapa, assumindo a própria vida:

\begin{abstract}
Assim, eu falei assim, chega! Eu quero ser eu, quero... quero me sentir, quero tomar as minhas decisões, quero respeito, quero ser responsável [...] E nisso em diante eu tenho tomado mais atitudes, mas tem um fortalecimento pra isso porque eu tô só com onze meses nessas atitudes todas (Thaís, informação verbal).
\end{abstract}

Além disso, afirma que os jovens podem experimentar muitas coisas, mas que precisam conhecer o seu limite. Ao ser questionada sobre como reconhece o seu limite, Thaís responde: "O meu limite é quando eu não me sinto mais eu, quando eu estou assim, mais falseta. Ai sim, eu sei que não é eu, não tem expressão mais meu sentimento, não estou sendo eu, estou sendo outra Thaís qualquer". Além disso, ela passou a colaborar com a acolhida dos jovens no espaço cultural e a utilizar sua história de vida como testemunho para outras meninas que passaram por experiências semelhantes à sua, dando novo sentido ao sofrimento vivido.

\subsection{Juliano}

Juliano tem 25 anos, é negro, magro e não muito alto. Possui um olhar atento, profundo e ao mesmo tempo vigilante em relação ao que acontece ao seu redor. Morou com sua família no bairro do Uruguai dos 4 aos 19 anos e sua casa localizava-se no "gueto", considerada à época, a região mais perigosa do lugar. Relata que, desde pequeno, ia caminhando de manhã sozinho para a escola e que tinha que passar pelas "bocas acesas" onde acontecia o comércio de drogas.

Eu já via em cada esquina os traficantes armados [...] nós viamos o dia a dia o tráfico de drogas, a violência [..... Eu saía pra ir pra escola sete horas da manhã e já via em cada esquina os traficantes armados - eles já nos cumprimentavam, nos respeitavam e a gente já saía cumprimentando os traficantes, mas também

\footnotetext{
6 Entrevista de Thaís concedida à pesquisadora Suzana Filizola Brasiliense Carneiro, no contexto da pesquisa de doutorado $A$ formação humana em contexto de violência: uma compreensão clinica a partir da fenomenologia de Edith Stein, na cidade de Salvador, BA, Brasil, no dia 10 de novembro de 2014

7 Entrevista de Thaís concedida à pesquisadora Suzana Filizola Brasiliense Carneiro, no contexto da pesquisa de doutorado $A$ formação humana em contexto de violência: uma compreensão clínica a partir da fenomenologia de Edith Stein, na cidade de Salvador, BA, Brasil, no dia 10 de novembro de 2014

8 Entrevista de Thaís concedida à pesquisadora Suzana Filizola Brasiliense Carneiro, no contexto da pesquisa de doutorado $A$ formação humana em contexto de violência: uma compreensão clínica a partir da fenomenologia de Edith Stein, na cidade de Salvador, BA, Brasil, no dia 10 de novembro de 2014.
} 
já tinha um certo tipo de medo, né? Medo porque nossa vizinha, a dona M., foi assassinada quando o Brasil foi campeão da Copa em 2012. Eu tinha doze, treze anos. Ela foi assassinada porque nessa época, nessa rua, o pessoal estava na porta dela cometendo todo tipo de tráfico, incomodando a vida dela... Ficavam fazendo barulho, algazarra, jogando pedra no telhado... Ela estava se sentindo incomodada e denunciou pros policiais. Os policiais chegaram a prender alguns deles [...] Eles foram soltos e por represália eles acharam por bem assassinar ela [...] Quando tinha denúncia anônima de vizinhos sobre traficantes, qualquer um de nós podia ser o suspeito... Então tinha aquele clima de insegurança [...] Eu tinha muito medo, até medo do meu pai ser assassinado. Porque eu sabia que, a qualquer momento, ele podia desconfiar de qualquer um dos moradores (Juliano, informação verbal). ${ }^{9}$

\section{Juliano era orientado pelos pais a evitar deter-} minadas regiões do bairro devido à rivalidade entre as facções criminosas. A esse respeito afirma:

Tinha um lugar muito legal que nós jogávamos futebol que nossos pais falavam: '-Não vai pra esse lugar, é o mais perigoso... É o matadouro. Vocês podem estar jogando lá e ver alguma coisa... podem querer botar vocês pra... também...' A gente era muito orientado dessa forma [...] Duas, três pessoas foram pegas, atingidas por balas e nós jogávamos bola perto. Então, tinha esse receio de estarmos naquele lugar e recebermos bala perdida. A qualquer momento podia ter uma guerra entre essas duas localidades [facções] (Juliano, informação verbal). ${ }^{10}$

\section{Conforme crescia, o medo de Juliano foi sendo} transformado e, aos 16 anos, as pessoas temidas passaram a ser admiradas:

Pessoalmente chegou um momento em que cedi nessa parte das amizades e comecei a ser influenciado... Eu passei a admirar esse lado do crime. Participei, por um momento, da criminalidade nesse local. Foi algo muito forte [...] Na época não era nada absurdo, já era tipo uma glória, participar do tráfico já tinha certo prestígio... Já era figura respeitada, ladrão respeitado, quem porta uma arma é respeitado. Tinha essa certa cobiça pra ter esse tipo de respeito, porque a pessoa que não participa disso é tachado como um... como um bobo, um otário (Juliano, informação verbal). ${ }^{11}$

Ele conta que começou a ter um comportamento violento e que, no início, isso o fez se sentir "meio pesado". Entre os 17 e 18 anos frequentou uma comunidade evangélica e afastou-se dessas atividades. Entretanto, começou a trabalhar em um mercado e com o salário comprou uma moto, que lhe trouxe prestígio e a vontade de ganhar mais:

\begin{abstract}
Isso era o que eu mais cobiçava: ter fama, ter mulheres, ter roupa de marca cara... Tive necessidade maior de correr atrás e ganhar mais, coisa que um salário mínimo, um emprego não daria conta... Então foram surgindo as oportunidades, as propostas [...] já estava cometendo delitos como roubos, interceptação de veículos... como eu tinha uma moto passei a me aproximar dessa parte de interceptação, com roubo de veículos (Juliano, informação verbal).12
\end{abstract}

Juliano conta que, aos poucos, esse tipo de atividade passou a fazer parte de sua rotina, "como uma profissão". Articulava roubos e crimes cada vez mais arriscados e rentáveis, e passou a fazer parte de uma quadrilha grande de Salvador, que se articulava com outros bairros e com presidiários. Acabou sendo preso ao assaltar o carro de um policial militar. A respeito dessa experiência relata:

[...] eu e um amigo meu de menor, fomos assaltar o veículo de um policial militar com objetivo de cometer outro delito maior e nós fomos presos. Ele (parceiro) foi atingido por três balas e eu tive um livramento e passei a ter mais consciência da vida, passei a me conscientizar mais da minha fragilidade - porque até então, tudo o que eu cometia, eu conseguia escapar, conseguia ter uma camuflagem, ninguém conseguia me capturar [...] Eu achava que nunca ia acontecer, achava que até mesmo a morte não ia acontecer pra mim. A autoconfiança começa a fazer parte da vida da pessoa que está cometendo esses crimes. Então, depois dessa experiência [...] eu tive uma consciên-

\footnotetext{
9 Entrevista de Juliano concedida à pesquisadora Suzana Filizola Brasiliense Carneiro, no contexto da pesquisa de doutorado A formação humana em contexto de violência: uma compreensão clínica a partir da fenomenologia de Edith Stein, Salvador, BA, Brasil, no dia 23 de julho de 2015.

10 Entrevista de Juliano concedida à pesquisadora Suzana Filizola Brasiliense Carneiro, no contexto da pesquisa de doutorado A formação humana em contexto de violência: uma compreensão clínica a partir da fenomenologia de Edith Stein, Salvador, BA, Brasil, no dia 23 de julho de 2015

11 Entrevista de Juliano concedida à pesquisadora Suzana Filizola Brasiliense Carneiro, no contexto da pesquisa de doutorado A formação humana em contexto de violência: uma compreensão clínica a partir da fenomenologia de Edith Stein, Salvador, BA, Brasil, no dia 23 de julho de 2015.

${ }_{12}$ Entrevista de Juliano concedida à pesquisadora Suzana Filizola Brasiliense Carneiro, no contexto da pesquisa de doutorado A formação humana em contexto de violência: uma compreensão clínica a partir da fenomenologia de Edith Stein, Salvador, BA, Brasil, no dia 23 de julho de 2015
} 
cia maior do perigo que eu estava correndo (Juliano, informação verbal). ${ }^{13}$

[...] nesse dia foi como um milagre porque nós não fomos mortos e além de ser pegos, uma moradora local interviu e não permitiu que o policial nos levasse pra nos matar [...] Eles mesmos (policiais) falaram que se eu caisse daquela moto, eles iam nos subtrair mesmo, nos matar mesmo, não iam ter piedade... Então tive essa experiência em que fui preso [...] isso nunca tinha acontecido comigo, de ser preso... Eu tive essa experiência muito terrivel na minha vida. Mas lá foi que eu tive a oportunidade de conhecer a realidade, acordar para a realidade que eu estava vivendo e decidir o que eu queria na minha vida: se eu queria realmente continuar nessa vida de trevas ou se eu queria uma mudança de vida pra que eu viesse esquecer todo passado e viver um novo caminho, um caminho de vitórias (Juliano, informação verbal).14

Na prisão, Juliano se converteu ao cristianismo e decidiu deixar o crime. Conta que, por seu comportamento "exemplar" na prisão, conseguiu diminuir a pena de dois anos para seis meses. Ao ser solto, Juliano passou a morar no centro da cidade onde hoje trabalha como guia turistico.

\section{Compreendendo as experiências à luz de uma psicologia inspirada em Stein e Giussani}

À primeira vista e em um olhar conduzido pelos fatos, os relatos de Thaís e de Juliano podem nos remeter à imagem de um mar revolto, cheio de ondas desgovernadas que se movem ao sabor do vento. Mas se ousamos adentrar nesse mar, nos deparamos com uma movimentação diferente, um fluxo mais estável e contínuo formado por correntes oceânicas profundas. Edith Stein e Luigi Giussani nos ensinam que a compreensão da experiência humana implica justamente a possibilidade de aquisição desse olhar amplo e profundo, capaz de ver além da materialidade e das explicações causais que a acompanham, para acessar a interioridade da pessoa e os movimentos complexos da alma. Implica em não pararmos na superficialidade dos comportamentos, mas a buscarmos acessar a estrutura das vivências, com os sentidos nelas impregnados, e que, como veremos, revelam um movimento essencialmente humano, em busca de realização.

Tanto Stein (1891-1942) como Guissani (19222005) nos oferecem uma visão antropológica enraizada na fenomenologia, capaz de embasar uma prática psicológica mais compreensiva em relação à experiência humana e com a possibilidade de uma tomada de posição mais justa de quem é acompanhado. Não sabemos se existiu alguma forma de influência dos estudos de Edith Stein sobre a antropologia de Giussani no reconhecimento da centralidade da chamada experiência elementar. Contudo, acreditamos que o pensamento desses dois autores pode se enriquecer e se complementar visto que, para ambos, a centralidade é a experiência, com os sentidos que nelas se desvelam. Ambos se dirigem ao âmbito da interioridade pessoal, se distanciando da leitura psíquica como se fossem fonte de interpretação ou explicação sobre causas e consequências, para pautar-se sobre as experiências de vida, que colocam em jogo algo que ultrapassa o plano intelectual para englobar também a dimensão emocional das vivências (MAHFOUD, 2019, p. 53-76).

Nesse sentido, podemos compreender a contribuição da fenomenologia para a psicologia como um convite a se ater à análise das vivências humanas, a acompanhar a pessoa livre de quadros teóricos pré-estabelecidos para deixar que ela se mostre na experiência que faz de si na relação com o mundo, com o outro e com a transcendência. É a partir dessa análise que Edith Stein nos apresenta a estrutura essencial da pessoa, constituida pelas dimensões corpórea, psiquica e espiritual, impossibilitando tratá-las isoladamente, mas sempre na compreensão de algo maior (CARNEIRO, 2016, p. 21). Essa estrutura universal aponta para a realidade da dimensão

13 Entrevista de Juliano concedida à pesquisadora Suzana Filizola Brasiliense Carneiro, no contexto da pesquisa de doutorado A formação humana em contexto de violência: uma compreensão clínica a partir da fenomenologia de Edith Stein, Salvador, BA, Brasil, no dia 23 de julho de 2015.

${ }_{14}$ Entrevista de Juliano concedida à pesquisadora Suzana Filizola Brasiliense Carneiro, no contexto da pesquisa de doutorado A formação humana em contexto de violência: uma compreensão clinica a partir da fenomenologia de Edith Stein, Salvador, BA, Brasil, no dia 23 de julho de 2015 
comunitária, que vivenciamos cada vez que experimentamos reconhecimento e proximidade diante do outro e da sua experiência. Ao mesmo tempo, Stein (2001) aponta para o caráter singular da pessoa ao revelar que essas dimensões estruturais se manifestam de maneira única em cada um. É possivel reconhecer quando alguém está triste, alegre ou ansioso, mas cada um vive a tristeza, a alegria ou a ansiedade ao seu modo único, de maneira que, juntamente com o reconhecimento da proximidade, experienciamos certo distanciamento que nos faz descobrir o outro como outro e, portanto, também o "eu".

"Eu" não é um "lugar físico" e nem algo fixo, mas a consciência que confere unidade às vivências e que se desloca a cada momento de acordo com nosso ponto de atenção. Segundo Stein (1997. p. 146), "o eu se manifesta como ponto móvel na alma", e a luz da consciência se acende onde ele se detém. Podemos nos deter na exterioridade ou na superfície da alma, abandonando-nos "ao nivel material do que vem a ser experienciado na vida cotidiana" (campo dos afazeres) e no apego às sensações, ou podemos nos ancorar na própria alma, entrando em nosso íntimo e acolhendo "a vida pessoal, livre e consciente acontecendo, emergindo de uma 'fonte secreta' em si [nós] mesmols]" (MAHFOUD, 2019, p. 64). Segundo Mahfoud (2019, p. 64), a própria experiência revela esse dinamismo do eu e nos solicita a elaborações mais complexas e à acolhida dessa vida pessoal que brota do nosso intimo. Nesse sentido, estando efetivamente presentes na ação que realizamos - prestando atenção à experiência - é possivel captar e acolher a nossa pessoalidade acontecendo.

Tal convocação da experiência nos remete à escuta do que Stein (2004, p. 132) chama de "pensamentos do coração" ou "vida originária da alma", que se torna acessivel a nós não como um pensamento articulado, e sim, como um apelo interior de realização de si, que se manifesta quando sentimos algo como impregnado de valor porque nos corresponde, nos ajuda a reconhecer quem somos e qual a direção do nosso vir-a-ser.

O ponto central então de um trabalho psico- lógico inspirado na fenomenologia de Stein e de Giussani, se coloca como reconhecimento dos fatores dinâmicos da experiência e da convocação à vida pessoal que ela faz. Mahfoud (2020, p. 75-83). propõe um trabalho de elaboração da experiência no horizonte da totalidade. Embasado em Stein, Mahfoud (2019, p. 66) afirma que, para que a pessoa possa conhecer a si mesma sem alienação e desenraizamento, deve fazer a experiência de empatia, um relacionamento onde ela pode vivenciar na abertura à exterioridade, a consciência de si mesma e de sua interioridade. $E$ aqui temos a posição do psicólogo como abertura ao acontecimento da experiência do outro, para sermos facilitadores da elaboração da experiência.

A partir da perspectiva de uma psicologia compreensiva apresentamos aqui o conceito de experiência elementar, que Mahfoud (2012, p. 31) trouxe para a psicologia e que nos ajuda no percurso da compreensão da experiência humana. Do ponto de vista proposto por Giussani (2009), a experiência elementar corresponderia a um conjunto de exigências originárias, constituintes do modo humano de ser, que estariam na base de todos os seus atos. Na constituição da pessoalidade humana, surgiriam, como manifestação essencial do modo humano de ser, exigências tais como a de liberdade, verdade, justiça, amor e beleza, entre outras. Tais exigências estariam sempre presentes no horizonte da experiência pessoal, como critérios a partir dos quais o vivido seria efetivamente julgado - mesmo que esse processo nem sempre se dê de modo consciente. Pode ser considerada um crivo, à luz do qual toda experiência seria considerada, por meio do que se torna possivel identificar, portanto, tanto a realização, um fruir da vida, como o sofrimento. Assim, como bem demonstra Mahfoud (2012, p. 57), configura-se como um posicionamento que pode orientar a clínica psicológica atual.

Guiando-nos por essas orientações, conseguimos identificar a exigência de ser em Juliano e Thais, na medida em que parece colocar-se sempre a partir de um critério muito preciso, mesmo que não conceitual ou discursivamente pensado, para afirmar "eu sou" ou "eu não sou", 
"sou algo grande" ou "sou a pior". Em muitas de suas declarações, vale dizer, de suas condutas, os dois jovens expressam o que podemos considerar como manifestação da exigência de ser. No caso de Juliano, quando ele se refere ao desejo de pertencer ao tráfico, entendemos como um desejo de ser valorizado, visto, olhado. E, nas situações de vida atual, tanto social quanto emocional, esse parece ser o caminho mais certo para tal conquista. Já a expressão desse desejo em Thais aparece como desejo de pertencimento, que ela busca incialmente na sua família de origem, quando vai à igreja, por exemplo, e se comporta como "cristã". Entretanto, ela não encontra essa pertença nem na igreja, nem na escola, e continua sua busca em novos contextos.

Mahfoud (2012, p. 55) afirma que não se trata de exigência de autonomia, mas de alcançar uma posição de dependência, uma vez que o humano, para ser, depende. De fato, para poder ser, preciso do outro que me receba no mundo, preciso que minha existência faça sentido verdadeiro no mundo e na história:

A formulação do sentido de minha existência depende de que ela faça diferença num certo contexto, de que faça diferença, que eu deixe minha marca. Sem ser recebido no mundo humano, eu não teria condições de exercer meu dinamismo próprio, não chegaria a ser eu mesmo. A exigência de ser é absolutamente radical: diante da impossibilidade, há a dor da não realização; mas a exigência não desaparece (MAHFOUD, 2012, p. 55).

Como vemos, partindo de uma visão ético-antropológica, passivel de ser trazida para a clínica psicológica, para ser utilizada como verdadeiro orientador de intervenções, Mahfoud (2012, p. 54) faz colocações que aparentemente nos remetem a condições que invocam o alcance de um certo amadurecimento emocional.

No caso de Juliano, a exigência de ser, cuja importância Mahfoud (2012, p. 55) destaca bem, mostra-se, no quadro pessoal caracterizado por tentativas, aparentemente desorientadas, de busca de soluções em um contexto social fortemente marcado pelo crime e pela garantia de sua realização como pessoa. Assim, não surpreende constatar que a necessidade de se constituir como singularidade pessoal venha a se expressar, na vida de Juliano, como luta incansável e desesperada pela obtenção de um olhar de entusiasmo, "glória", importância, honra que esse mundo traz. Na luta por esse olhar, várias estratégias foram usadas, como a compra da moto, o uso de armas e a participação em crimes cada vez mais articulados e perigosos.

Dessa feita, podemos afirmar que Juliano se apresenta profundamente tocado, de modo direto, sensivel e intuitivo, por uma exigência fundamental de ser, que não se encontra contemplada em sua própria vida. Por outro lado, aventura-se em caminhos, possivelmente equivocados, na medida em que assimila imaginários coletivos prevalentes na sociedade em que vive. Um processo psicoterapêutico poderia beneficiá-lo por meio do reconhecimento da exigência, como recomenda Mahfoud (2012, p. 90), do holding e do manejo de sua ansiedade, que proporcionariam incremento de esperança e coragem para examinar as fantasias que correspondem a falsas soluções, e posicionar-se diferentemente na vida.

Já Thais parece ter uma percepção mais sensivel quanto a esse crivo originário e na busca por sua realização, tanto que em muitos momentos de solidão seu relato é de que ela "dança", buscando dentro de si, algo que corresponda a esse desejo. No início uma busca solitária e dentro de si, mas que por fim leva a concretude encontrando um espaço de acolhida para si. Essa sensibilidade com a própria experiência elementar se vê quando ela diz "o meu limite é quando eu não me sinto mais eu".

Mahfoud (2012, p. 94) afirma que, para ajudarmos o outro, trilharíamos um caminho promissor se pudéssemos compreender a experiência de dor para explicitar a exigência, a urgência que vibra em uma dada tristeza, angústia ou desespero. Desse modo, poderíamos explicitar o bem ausente que está sendo exigido ou, conforme Stein, os sentidos que brotam do apelo da vida originária da alma, auxiliando a pessoa a ampliar as possibilidades de realização desse sentido. Como todas as pessoas Juliano busca, a nosso ver, um lugar onde possa realizar sua exigência 
de ser. Ocorre, contudo, que insiste em uma procura de que a exigência seja atendida no contexto do relacionamento com o crime, cuja realização nunca se teria, a seu ver, cumprida. De todo o modo, imaginar que sua questão só se resolveria no sucesso dessa vida no crime, ou quando tivesse o corpo perfeito (no caso de Thaís) corresponde a um equívoco, pois são muitas as oportunidades passiveis de favorecer experiências de encontro consigo mesmo, ainda que evidentemente limitadas pelas condições de vida prevalentes na sociedade.

No caso de Juliano a igreja se tornou esse lugar de encontro consigo mesmo, que possibilitou o reconhecimento, senão das exigências propriamente ditas, mas do incômodo e da não conformidade naquela forma de vida. Vale também chamar atenção para a intervenção de "uma moradora" que impediu que a polícia o matasse, realizando um gesto de acolhida de Juliano no mundo e de afirmação do sentido de sua existência. No caso de Thaís, foi a experiência no Espaço Cultural que lhe deu essa oportunidade de encontro consigo mesma. Thaís afirma que ali foi acolhida como um ser humano, tendo encontrado o seu mundo e sua vida.

Pensando na contribuição da psicologia em situações semelhantes às desses jovens, caso a pessoa possa chegar à psicoterapia, o posicionamento do terapeuta será fundamental, visto que, antes de mais nada, deve tornar-se disponivel para verdadeiramente acolhê-la e acompanhá-la. Estar com é o modo como estamos compartilhando a condição humana, ou seja, compreender que aquela questão que o paciente traz é ao mesmo tempo dele, e é também de todos os seres humanos na medida em que compreendemos as exigências como algo inerente a toda e qualquer pessoa. Esse modo de estar com o paciente é percebido por ele independentemente de sua situação existencial ou psíquica; pois, nessa perspectiva, a questão originária seria o elemento que move qualquer processo terapêutico, quer disso se tenha consciência ou não. Apresentando-se, no aqui e agora da sessão, como peculiar à pessoa atendida, consiste ao mesmo tempo em uma das questões que atravessam toda a humanidade (MAHFOUD, 2012, p. 97). Trata-se de uma clínica que faz uso da compreensão da experiência vivida, sempre mais ampla do que aquilo que pode ser conscientemente percebido, a partir de uma visão que privilegia os vínculos afetivos próximos, conforme o paradigma relacional (GREENBERG; MITCHELL, 1994) sem descurar das condições concretas da vida social. Compreendendo como lugar de experiência de acolhimento e não de obtenção de explicações analíticas sobre determinadas condutas.

O acolhimento ocorre, na perspectiva de Mahfoud (2012, p. 56), quando o terapeuta pode identificar o bem ausente buscado pelo paciente, ainda que por caminhos equivocados e sofridos. Compreender essa dor seria, em outras palavras, não fugir da verdade emocional ou evitar defesas que nos distanciem da verdadeira experiência que está sendo vivida. A seu ver, não se trata de valorizar o sofrimento por si só, mas acolhê-lo a fim de que nos mostre aquilo que nos falta, o bem essencial para nossa realização, gerando, então, um movimento de procura. É entrando em contato próximo e profundo com a totalidade da sua experiência que o paciente vem a apreender seu significado e a descobrir novos recursos pessoais para lidar com sentimentos e circunstâncias.

\section{Considerações finais}

Casos como o de Juliano e de Thais, demonstram a necessidade de abandonarmos um olhar esquemático, que aposta que mudanças desejáveis serão alcançadas por caminhos essencialmente cognitivos, para adotar uma visão mais abrangente, que inclua complexidades da vida emocional, que se encontram na base das dificuldades.

Como vimos, essa visão mais abrangente é possivel a partir de uma psicologia que coloca a experiência no centro e que é capaz de ajudar o jovem a reconhecer e a exercer seu dinamismo próprio, realizando a si mesmo e deixando sua marca no mundo. Trabalhando assim, o psicólogo oferece um encontro humano que se torna "lugar" de compreensão e de acolhida, e não de julga- 
mento, e que possibilita ao jovem acolher suas experiências como possibilidades de realização de sentido, mesmo aquelas que são vivenciadas como sofrimento e falta.

\section{Referências}

CARNEIRO, Suzana F. B. A formação humana em contexto de violência: uma compreensão clínica a partir da fenomenologia de Edith Stein. 2016. 322 p. Tese (Doutorado em Psicologia) - Programa de Pós-Graduação em Psicologia Clínica, Instituto de Psicologia da Universidade de São Paulo, São Paulo, 2016. Disponivel em: https:// www.teses.usp.br/teses/disponiveis/47/47133/tde16082016-115100/pt-br.php. Acesso em: 16 fev. 2020.

GIUSSANI, Luigi. O senso religioso. Brasília, DF: Universa, 2009.

GREENBERG, J. R.; MITCHELL, S. A. Relações objetais na teoria psicanalitica. Porto Alegre: Artes Médicas, 1994.

MAHFOUD, Miguel. Reconhecer o movimento do eu: processos psicoterápicos. In: ANGERAMI, V.A. (org.). Atualidades em psicoterapia fenomenológico-existencial. Belo Horizonte: Artesã, 2020. p. 75-83

MAHFOUD, Miguel. Gesto fenomenológico diante do acontecimento da subjetividade. In: FEIJOO, A. M. L. C.: Lessa, M. B. M. F (org.). O gesto fenomenológico: corpo, afeto e discurso na clínica. Rio de Janeiro: IFEN, 2019. p. 53-76.

MAHFOUD, Miguel. Experiência Elementar em psicologia: aprendendo a reconhecer. Belo Horizonte, MG: Artesã, 2012.

STEIN, Edith. A ciência da cruz. São Paulo: Loyola, 2004.

STEIN, Edith. Introduzione alla filosofia. Roma: Città Nuova, 2001

STEIN, E. Il castello interiore. In: STEIN, Edith. Natura, persona e mistica. Roma: Città Nuova, 1997. p. 115-147.

\section{Suzana Filizola Brasiliense Carneiro}

Doutora em Psicologia Clínica pela Universidade de São Paulo (USP), em São Paulo, SP, Brasil; psicóloga clínica e professora no curso de Psicologia da Universidade Paulista (UNIP), em Santos, SP, Brasil.

\section{Maria Camila Mahfoud Marcoccia}

Mestre em Psicologia Clínica pelo Instituto de Psicologia da Universidade de São Paulo (USP), em São Paulo, SP, Brasil; psicóloga clínica.

\section{Endereço para correspondência}

Suzana Filizola Brasiliense Carneiro

Universidade Paulista - Campus Rangel

Avenida Francisco Manoel $\mathrm{s} / \mathrm{n}{ }^{\circ}$

Vila Matias, 11075110

Santos, SP, Brasil

Maria Camila Mahfoud Marcoccia

Consultório Particular

Av. Angélica, 1996/2000, cj 708

01227906

São Paulo, SP, Brasil 